\title{
It's a good idea to criminalise purchase and possession of tobacco by minors - NOT!*
}

\author{
Julia Carol
}

At any given moment, thousands of people are suffering painful illness and some are dying from a variety of tobacco-related diseases. Family members are grieving, their loss is a permanent scar. At the same moment our children are viewing glitzy billboards and advertisements encouraging them to smoke. Some are becoming the next generation of addicts who will suffer painful illnesses and die, leaving future families to grieve. It is a morbid cycle.

It is no wonder that we are angry, frustrated, and willing to resort to a barrage of methods to stop the pain, the suffering, and the needless death. Having only limited stones to throw, David, I'm sure, aimed carefully before firing at Goliath - and so must we.

Most of us recognise that prohibition of tobacco isn't feasible. Our goal, then, is to motivate society to reject tobacco use. But how?

We have some areas of success. Eliminating advertising, sponsorship, and promotion of tobacco products has proved to be effective in some countries. Raising the excise tax on cigarettes has also proved to be effective at reducing consumption. In the United States passage of smoking control laws has protected the public from environmental tobacco smoke and has also served to reduce the social desirability of smoking. It seems wise to continue to work on these goals in places where they have not yet been adopted.

Yet, we have not been as obviously successful at raising a new generation who remain unaddicted to tobacco. We are in a race to reach our children before the tobacco industry does - and so far the industry is winning.

The strategies for reaching children may be divided into two key areas: eliminating the demand (prevention) and eliminating the supply (protection, or access to tobacco). We stand the best chance for success if we marry these two strategies, while keeping in mind the following:

- Before embarking on any programme to reach children it is crucial that we remember our audience (youth) and our enemy (the tobacco industry)

- The young people most at risk of tobacco

Americans for Nonsmokers' Rights, 2530 San Pablo Avenue, Suite J, Berkeley, California 94702, USA

J Carol

* A current fad among young people in the United States, created by the film "Wayne's World," is to state a mistruth or exaggeration followed by an emphatic "NOT!" addiction often ( $a$ ) have low expectations of themselves and others and don't see many options available to them; (b) are under multiple stressors from their social environments; $(c)$ are not doing well in school; and $(d)$ lack the motivation or skills, or both, to make healthy decisions. When working with young people our efforts can be designed to help alleviate these factors and should never exacerbate them

- The tobacco industry portrays tobacco use as an initiation into a romanticised adulthood which promises sexual fulfilment, athletic prowess, plenty of freedom, fun, and some rebellion. The slick advertisements promise girls that they will stay thin and boys that they will be rugged. They will look grown up, independent, chic, and in control. We should never do anything that helps the industry perpetuate these powerful myths.

The plan to criminalise purchase and possession of tobacco by minors, which is the subject of this debate, is a protection strategy. How do we evaluate its merits?

Evaluating the merits of a given tobacco control programme can be accomplished using two simple tests. Firstly, place the burden of proof on the strategy: instead of asking "why not do it?" we ought to begin by asking "why do it?" Unless there are clearly compelling reasons, pick a different strategy.

Secondly, is there a downside - that is, is it possible the proposed programme will have a negative impact (like worsening any of the high risk factors listed above or playing into the tobacco industry's hands)? Are there better ways to achieve the same goal?

Let us put criminalising purchase and possession of tobacco by minors to the tests.

WHY DO IT?

Proponents' main argument is that criminalising possession of tobacco by minors is a deterrent against their use of tobacco. They do not want to punish the victims and they are not suggesting that children be arrested and hauled into court. They believe that once children find out that it is illegal to be caught with the contraband tobacco on their person, they will see the error of their ways and choose wisely to remain tobacco-free.

This argument strains credulity. Remember

Thiseup of the children at risk? There is no reason to believe that criminalising possession will provide significant deterrence. 
The strategy of criminalising possession of tobacco fails the first test and would not be worth the time and energy to implement. But criminalising purchase and possession by minors isn't just ineffective. Let us finish the test.

\section{IS THERE A DOWN SIDE, OR A POSSIBLE} DELETERIOUS EFFECT?

As a society, we allow little Mary to be bombarded daily with an effective barrage of tobacco industry con artistry designed to grab her. If she is lucky, she might go to a school that spends one hour a day for five days a year on a smoking prevention programme. Once she is hooked there is probably no cessation programme available. If there is, it probably wasn't designed specifically for young people. We have failed her. She becomes addicted. She knows of nowhere to go for help. Now we are going to tell her that she is a law breaker because she smokes.

The enforcement issue is another negative. Either the law provides for enforcement or it does not. If it does not, it sends the message that we are not serious about the tobacco control policies we promote. If strong enforcement language is a part of the law, is it feasible? Evidently, the New Hampshire state legislature decided that it was not, citing a lack of enforceability as the reason to repeal the state's possession law. And what about places where the law is enforced? Our children will be stopped by police and ticketed. Sure, they might do community service or receive some other "useful" punishment. But the message is the same - they are the bad guys.

Plain and simple, the formative years are more than just a time when young people decide whether or not to experiment with tobacco: they are the time other decisions about identity are made. It is a terrible idea to help a young person identify herself as a law breaker.

And what message are young people receiving about tobacco under a criminalisation scheme? Only one: they cannot smoke because they are not old enough. It is foolish to reinforce the cigarette companies' advertisements portraying tobacco use as adult behaviour.

ARE THERE BETTER WAYS TO ACHIEVE THE SAME GOALS?

Yes! Pick from the following, or create your own. Successful minors' access programmes include raising the cigarette excise tax, banning cigarette vending machines, banning free sampling of cigarettes, strict licensing requirements for merchants who sell tobacco, and enforcing sales-to-minors laws (which put the onus on the vendor, not the young people). Successful prevention programmes include a smoking prevention curriculum; out-of-school programmes for children; and banning advertising, sponsorship, and promotion of tobacco products. Even passage of clean indoor air legislation serves as prevention because it removes a great deal of modelling behaviour while reinforcing the social undesirability of smoking. It also protects our children from secondhand smoke. (You get a lot of "bang for your buck" by passing strong smoking restriction laws.)

In summary, it's doubtful that criminalising purchase and possession is really a deterrent. There are better ways of reaching young people. And, more importantly it is a dirty trick to blame young people for falling prey to an industry that society lets run amok. 